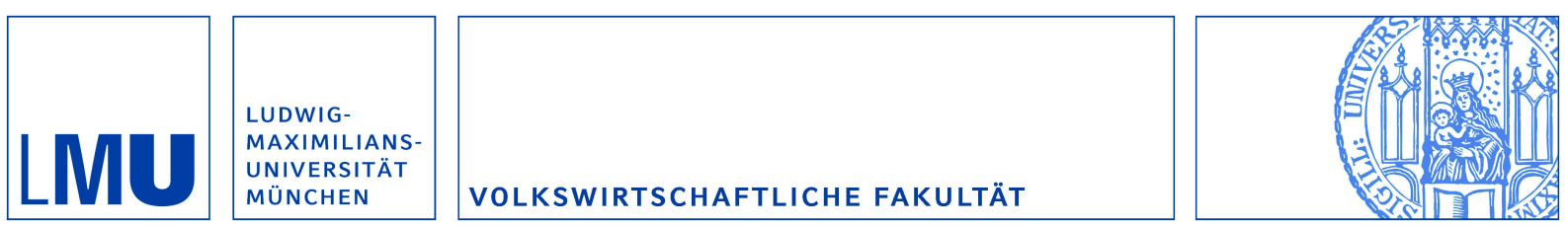

Bartling, Björn und Schmidt, Klaus M.:

Reference Points in Renegotiations: The Role of Contracts and Competition

Munich Discussion Paper No. 2012-27

Department of Economics

University of Munich

Volkswirtschaftliche Fakultät

Ludwig-Maximilians-Universitäł München

Online at https://doi.org/10.5282/ubm/epub. 14192 


\title{
Reference Points in Renegotiations:
}

\section{The Role of Contracts and Competition*}

\author{
Björn Bartling ${ }^{\text {a) }}$ and Klaus M. Schmidt ${ }^{\text {b) }}$
}

August 3, 2012

\begin{abstract}
Several recent papers argue that contracts provide reference points that affect ex post behavior. We test this hypothesis in a canonical buyer-seller relationship with renegotiation. Our paper provides causal experimental evidence that an initial contract has a highly significant and economically important impact on renegotiation behavior that goes beyond the effect of contracts on bargaining threatpoints. We compare situations in which an initial contract is renegotiated to strategically equivalent bargaining situations in which no ex ante contract was written. The ex ante contract causes sellers to ask for markups that are 45 percent lower than in strategically equivalent bargaining situations without an initial contract. Moreover, buyers are more likely to reject given markups in renegotiations than in negotiations. We do not find that these effects are stronger when the initial contract is concluded under competitive rather than monopolistic conditions.
\end{abstract}

Keywords: renegotiation, bargaining, reference points, contracts, competition JEL: C78, C91, D03, D86

\footnotetext{
* We would like to thank Ernst Fehr, the participants of the Copenhagen symposium on "Behavioral Theory of Institutions," the Budapest workshop on "The Social Dimension of Organizations," and seminar participants at Konstanz, Maastricht, and Prague for helpful comments and suggestions. Financial support from the Deutsche Forschungsgemeinschaft through SFB-TR 15 and the Excellence Initiative of the German government through MELESSA is gratefully acknowledged.

a) Björn Bartling, Department of Economics, University of Zurich, Blümlisalpstrasse 10, CH-8006 Zurich, Switzerland, email: bjoern.bartling@econ.uzh.ch

b) Klaus M. Schmidt, Department of Economics, University of Munich, Ludwigstrasse 28, D-80539 Munich, Germany, email: klaus.schmidt@1mu.de (corresponding author)
} 


\section{Introduction}

How do long-term contracts affect behavior? The traditional view held by most economists is that a contract affects the behavior of the contracting parties by changing the threatpoint of future renegotiations. ${ }^{1}$ For example, if a buyer and a seller write a contract requiring the seller to deliver some quantity $x$ of a good to the buyer at some future date and the buyer to make some payment $p$ in return, then each party can insist that this trade is carried out. If trading $x$ is efficient, this is what parties will do, but if a state of the world materializes in which trading $x$ is inefficient, then parties may renegotiate. In this case the threatpoint of the renegotiation game is that the initial contract is carried out. Thus, different contracts give rise to different threatpoints of future renegotiation which in turn affects how the surplus from renegotiation is split. Rational parties anticipate this and design the initial contract so as to give optimal incentives for relationship specific investments or to provide optimal insurance.

In a recent paper, Hart and Moore (2008) point out an additional role of long-term contracts. They argue that a contract defines a reference point that shapes the expectations of the contracting parties. Each party will evaluate the final outcome in comparison to what it feels entitled to by the initial contract. If a party gets less than what it feels entitled to it is aggrieved and "shades" its performance which gives rise to an ex-post inefficiency. Parties anticipate this and design the initial contract so as to optimally manage expectations.

The Hart-Moore (2008) approach is intriguing. It offers an explanation for ex post inefficient behavior and it has important implications for how these ex post inefficiencies are affected by different contractual arrangements, including the internal organization of firms. ${ }^{2}$ However, the approach is also controversial because there is little direct empirical evidence supporting the theory.

In this paper we put the basic premise of the Hart and Moore (2008) approach to an experimental test. Do contracts have an effect on behavior and final outcomes that goes beyond their effect on the threatpoint of renegotiation? To answer this question we abstract from the details of the Hart-Moore model and consider a canonical buyer-seller relationship in two experimental treatments. In our first treatment, the Contract Treatment, the buyer and the seller write an initial contract in an uncertain environment. Then the state of the world materializes. If it turns out that the initial contract is inefficient the parties can renegotiate. If they fail to reach an

\footnotetext{
${ }^{1}$ See, e.g., Grossman and Hart (1986) and Hart and Moore (1988).

${ }^{2}$ See Hart and Holmström (2010).
} 
agreement the initial contract is carried out. Thus, at the renegotiation stage the initial contract defines a bargaining game in which each party has a well-defined threatpoint. In our second treatment, the No Contract Treatment, there is no initial contract. The buyer and the seller meet only after the state of the world has materialized and negotiate how to split a surplus that is, by design, identical to the surplus in the Contract Treatment. If negotiations fail each party gets an exogenously assigned outside option payoff. The outside options in the No Contract Treatment are, by design, exactly the same as the threatpoint payoffs in the Contract Treatment that were generated endogenously by the initial contract. Thus, the strategic situation and the material payoffs of the renegotiation game in the Contract Treatment and of the bargaining game in the No Contract treatment are identical. If we observe that parties behave differently in the Contract Treatment as compared to the No Contract Treatment it cannot be due to the threatpoint effect. The initial contract must have an additional effect as predicted by the hypothesis that contracts serve as reference points.

In the experiment we find strong and clean evidence that the role of contracts goes far beyond the effect on outside options. In the renegotiation game of the Contract Treatment sellers make markup offers that are on average 45 percent lower than the "markups" offered by sellers in the bargaining game of the No Contract Treatment - even though the strategic situation is exactly the same in both treatments. ${ }^{3}$ Moreover, for given markups buyers are more likely to reject an offer in the Contract Treatment than in the No Contract Treatment. But since markup offers are so much lower in the Contract Treatment the average rejection rate is about the same in both treatments.

A second hypothesis of Hart and Moore (2008) is that it is important how the initial contract has been formed. They claim that a contract that was written under competitive conditions provides an objective measure of what the buyer and the seller bring to the relationship. Thus if there is ex ante competition the initial contract has a stronger impact on expectations and entitlements than if there is no competition ex ante. We test this hypothesis by comparing the Contract Treatment to a third treatment, the Contract\&Competition Treatment. In the Contract Treatment the seller is a monopolist who makes a take-it-or-leave-it offer to the buyer for the initial contract. In the Contract\&Competition Treatment there is competition between sellers for making an offer at the initial contracting stage, which leads to lower initial

\footnotetext{
${ }^{3}$ In the Contract Treatment, the markup is defined as the change in price compared to the initial price. In the No Contract Treatment, the markup is defined as the change in price relative to an exogenously given price that is identical to the price offer in the Contract Treatment.
} 
prices. At the renegotiation stage the winning seller is in a bilateral relation with the buyer, exactly as in the Contract Treatment. Comparing the markups charged by sellers in the renegotiation games in these two treatments we find that markups are much higher with ex ante competition. Thus, some of what the buyers gain by ex ante competition is lost again in the renegotiation game.

However, it cannot be concluded from this observation that the initial contract has less of an effect on the renegotiation outcome in the Contract\&Competition Treatment than in the Contract Treatment. The higher markups under competition could be due to the fact that initial prices are much lower with ex ante competition so sellers may want to compensate for the lower prices by charging higher markups in the renegotiation game. To control for this effect we conducted a final treatment, the No Contract\&Competition Treatment, in which there is no initial contract and the exogenously assigned outside options in the negotiation game are, by design, the same as the endogenously determined outside options in the Contract\&Competition Treatment. Also the surplus to be generated is identical in both treatments. Comparing the difference in markups between the Contract and No Contract Treatments to the difference in markups between the Contract\&Competition and No Contract\&Competition Treatments we find that both differences are large and highly significant, but that, if anything, the difference under competition is smaller. Thus, our experiment does not confirm the hypothesis that competition strengthens the effect of the initial contract.

There are several models trying to capture the idea that contracts provide reference points that affect the behavior of the contracting parties. All of these models consider specific contractual situations and are based on different behavioral assumptions. Hart and Moore (2008) consider "at-will contracts" that each party can walk away from at no cost. They compare rigid contracts that specify a fixed price $p$ to flexible contracts specifying a price range $[\underline{p}, \bar{p}]$ and giving one party the right to choose any price out of this interval. The behavioral assumption is that parties have self-serving biases, i.e., each party feels entitled to the best possible outcome that is feasible under the initial contract. If a party gets less than what it feels entitled to it is aggrieved and "shades" its performance. Importantly, shading is assumed to be costless.

In a closely related paper Hart (2009) considers a different set-up. He assumes that parties write contracts that are enforced by the courts and that these contracts can be renegotiated. 
However, if one party enters the renegotiation stage the other party considers this to be an attempt of hold-up. It is assumed that in this case all trust is lost and parties are no longer willing to provide "noncontractible helpful actions." Providing these helpful actions involves no costs but gives a large benefit to the other party.

Herweg and Schmidt (2012) develop a very different model of ex post inefficient renegotiations that is based on loss aversion, a fundamental concept in behavioral economics and psychology. In their model there is no second stage at which the parties can shade or withhold noncontractible helpful actions. They consider a "specific-performance contract" (that can be enforced by each party) and assume that parties compare any renegotiation outcome to the outcome prescribed by this initial contract. If the initial contract turns out to be inefficient and if the seller proposes to adjust the specification of the good to the state of the world provided that the buyer pays a higher price, then the buyer feels both a loss (because he has to pay more) and a gain (because he gets a better product). However, losses loom larger than equally sized gains. This drives a wedge between the costs and benefits of renegotiation giving rise to an inefficient outcome. It also restricts the price increase that the seller can charge and makes prices sticky.

All three models share the prediction that the initial contract affects the behavior of the contracting parties not just by affecting the threatpoint of the renegotiation game but also by setting a reference point. It is this basic premise that we put to a clean experimental test. Our experiment therefore abstracts from the specific assumptions imposed by the different models and focuses on the behavioral effect of the initial contract on the renegotiation game.

Our paper is closely related to a sequence of papers by Fehr, Hart and Zehnder (2009, 2011, 2012). FHZ (2011) design an experiment that closely follows the specific set-up of the Hart and Moore (2008) model. The question is whether a rigid contract performs better than a flexible contract. The experiment confirms that flexible contracts give rise to more "shading" than rigid contracts which makes rigid contracts more profitable for the buyers. FHZ (2009) discuss the role of competition by comparing the original experiment to a control treatment in which the contract is not written under competitive conditions but rather imposed exogenously on the parties. It is shown that the difference in shading between flexible and rigid contracts disappears in the control treatment. However, the control treatment differs in two dimensions from the original experiment. There is no competition and there is no voluntary agreement to the terms of the 
contract. Thus, it is not clear whether it is competition or voluntary agreement that is driving the treatment effect.

The problem with flexible contracts is that they leave room for different interpretations and different expectations. In FHZ (2012) the buyer can announce what prices he wants to set in the different states of the world. This announcement is voluntary and not binding. FHZ (2012) find that the announcement helps to coordinate expectations and to reduce the amount of shading under flexible contracts, but the basic tradeoff is still visible and significant. Brandts, Charness and Ellman (2012) put this result into question. They consider a slightly different experiment in which the buyer and the seller can freely communicate how they intend to use the flexibility of the contract. They find that with free communication flexible contracts are much more efficient than rigid contracts and that they are chosen considerably more often.

Erlei and Reinhold (2011) point out that if the buyer chooses a rigid contract in the FHZ (2011) experiment then the price is driven down by competition and the seller gets almost nothing of the surplus. If the buyer wants to give some of the surplus to the seller he must opt for a flexible contract and use the flexibility to increase the price. Thus, a rigid contract may trigger negative reciprocity while a flexible contract may be perceived as a signal of fairness. They confirm this hypothesis by comparing the original FHZ (2011) experiment to a control experiment in which contracts are assigned exogenously.

All these papers compare flexible and rigid contracts and study under what conditions flexible contracts give rise to shading. They show that there is indeed a tradeoff between flexibility and shading, but none of the papers allows for renegotiation. ${ }^{4}$ Our experiments focus on how negotiation behavior is affected by an initial contract, i.e. at the difference between negotiation and renegotiation. We show that the initial contract has a strong effect on bargaining behavior in the renegotiation game that goes far beyond the threatpoint effect. This result holds in a canonical buyer-seller relationship with specific-performance contracts even without the possibility of shading or noncontractible helpful actions.

Hoppe and Schmitz (2011) consider option contracts as a remedy to solve the hold-up problem. Standard theory predicts that option contracts are useless if they can be renegotiated. However, Hoppe and Schmitz show that option contracts still have an effect even with

\footnotetext{
${ }^{4}$ It not clear what the difference between a rigid and a flexible contract is if the rigid contract can be renegotiated. See HM (2008, p. 29-32) for a discussion of three possible interpretations. FHZ (2012) have a treatment in which the buyer can "repudiate" the initial contract, i.e. the buyer can unilaterally change the price without asking the seller for his consent. They show that the possibility of repudiation does not affect the basic tradeoff between flexible and rigid contracts.
} 
renegotiation, which is consistent with Hart and Moore (2008) and with our experimental findings. However, Hoppe and Schmitz focus on an option contract the terms of which are exogenously given, while we consider standard specific performance contracts that are endogenously negotiated by the contracting parties. ${ }^{5}$

The rest of the paper is organized as follows. Section 2 describes the experimental set-up. In Section 3 we compare the theoretical predictions of the self-interest model and of models of (outcome-based) social preferences to the predictions of Hart and Moore (2008) and Herweg and Schmidt (2012). Sections 4 and 5 report our experimental results. Section 6 concludes.

\section{Experimental Design and Procedures}

The experiment considers a trading relationship between a buyer and a seller with the following framing. The parties want to trade a good next week, but they do not know yet what the optimal day for delivery is. If the good is delivered on the "right day," the buyer's valuation of the good is $v=100$; if it is delivered on the "wrong day" the buyer's valuation is $v=50$. The parties know that Wednesday is the right day with 40 percent probability. However the right day may also be one of the other four workdays, each with probability 15 percent. The parties must write a contract that specifies the day of delivery before knowing what the right day is, but they know that the contract can be renegotiated.

If the good is delivered on Wednesday the seller's cost is $c=20$. If the good is delivered on some other workday the seller's cost are a random variable drawn from $[0,40]$ with $E(c)=20$ , i.e. costs may be a little higher or a little lower than 20 .

The time structure of the Contract Treatment (CT) is as follows:

Stage 0: A buyer and a seller are randomly matched. The seller makes a take-it-or-leave-it price offer $p$ for delivery on Wednesday. The buyer may accept or reject this contract. In case of rejection both parties get a payoff of 0 and the game ends. If the buyer accepts the game moves on.

\footnotetext{
${ }^{5}$ Our paper is also related to a field experiment on renegotiation and hold-up by Iyer and Schoar (2010). They report that wholesalers of custom-made pens in India often refuse to renegotiate the price when they are faced with a holdup situation. This is reminiscent of the higher rejection rates for given markups in our Contract Treatment as compared to the No Contract Treatment.
} 
Stage 1: Both parties learn the right day and the seller's cost of delivery on that day. If the right day is Wednesday the contract is executed and the game ends. In this case payoffs are $M^{S}=p-20$ for the seller and $M^{B}=100-p$ for the buyer. If Wednesday is not the right day the buyer can ask the seller to change the day of delivery to the right day. If the buyer does not ask for a change of the day of delivery or if the seller insists to deliver on Wednesday the contract is executed and the game ends. The resulting payoffs are $M^{S}=p-20$ for the seller and $M^{B}=50-p$ for the buyer.

Stage 2: If the buyer asks for a change of the day of delivery and if seller is in principle willing to comply with the request, the parties enter the renegotiation game in which the seller has two options:

1. He can make a take-it-or-leave-it renegotiation offer to the buyer, proposing to deliver the good on the right day if the price is changed to $p+m$, where $m$ is a markup that may be positive or negative. If the buyer accepts the offer, monetary payoffs are $M^{S}=p+m-c$ and $M^{B}=100-p-m$. If the buyer rejects, the initial contract is executed: the good is delivered on Wednesday and payoffs are $M^{S}=p-20$ and $M^{B}=50-p$.

2. He can simply deliver the good on the right day at the price specified in the initial contract, i.e. without asking for a markup. In this case the markup is zero and the seller's monetary payoff is $M^{S}=p-c$ while the buyer gets $M^{B}=100-p$.

Subjects play this game repeatedly for 24 rounds under a stranger matching protocol.

We compare the Contract Treatment to a No Contract Treatment (NCT) in which the parties do not write an initial contract. Parties meet only after the state of the world has materialized. We design this treatment such that the renegotiation game in CT at stage 2 and the bargaining game in NCT have exactly the same structure. Thus, we assign the outside options of the buyer and the seller in NCT as follows: For each buyer-seller pair in CT the price signed in the initial contract gives rise to a threatpoint $\left(\underline{M}^{B}=50-p, \underline{M}^{S}=p-20\right)$ in the renegotiation game. We assign this threatpoint exogenously to the corresponding buyer-seller pair in NCT. ${ }^{6}$

\footnotetext{
${ }^{6}$ We used the same matching protocol in CT and in NCT. Furthermore, the sequence of rounds such as the cost realizations was the same in all sessions. Thus, if seller $s$ is matched to buyer $b$ in period t of session $j$ in CT and his offer $\tilde{p}$ is accepted, then there exists a seller $s^{\prime}$ and a buyer $b^{\prime}$ in session $j$ of NCT, such that seller $s^{\prime}$ and buyer $b^{\prime}$
} 
Also the surplus that can be generated is identical in CT and NCT. As at stage 2 in CT, if the seller wants to trade he has two options:

1. He can make a take-it-or-leave-it offer to the buyer, proposing to deliver the good at price $\hat{p}$. If the buyer accepts the offer, the monetary payoffs are $M^{S}=\hat{p}-c$ and $M^{B}=100-\hat{p}$. If the buyer rejects, the exogenously given threatpoint is realized and payoffs are $M^{S}=p-20$ and $M^{B}=50-p$.

2. He can deliver the good without changing the exogenously given price $p$. In this case his monetary payoff is $M^{S}=p-c$ and the buyer gets $M^{B}=100-p$.

Note that the bargaining game in NCT and the renegotiation game in CT have the same strategic structure and exactly the same monetary payoffs. The "markup" in NCT is just the difference between $\hat{p}$ and $p$, i.e. $m=\hat{p}-p$. If the seller does not change the exogenously given price $p$, the markup is zero.

Furthermore, if the buyer rejected the seller's initial price offer at stage 0 in CT or if Wednesday is the right day in a given round in CT, then the corresponding buyer and seller in NCT are assigned the respective payoffs of CT exogenously and are informed that there is no trading opportunity in this round but that they get some exogenously given payoffs.

We conducted two sessions each of CT and NCT with 24 participants in the first session and 22 in the respective second session. We implemented three matching groups in each treatment. ${ }^{7}$ Upon arrival in the lab, half of the subjects were randomly and anonymously assigned the role of a buyer, the other half the role of a seller. We also conducted two sessions of the Contract\&Competition Treatment in which sellers competed at stage 0 for making an initial offer to the seller and two corresponding sessions of the No Contract\&Competition Treatment. ${ }^{8}$ The competition treatments are described in more detail in Section 5. The experimental instructions for all treatments can be found in the supplementary appendix.

All sessions lasted between 1.5 and 2 hours. They took place at the MELESSA laboratory of the University of Munich. Subjects were students of the University of Munich and the

have the exogenously assigned outside options $\underline{M}_{t}^{S}=\tilde{p}-c$ and $\underline{M}_{t}^{B}=50-\tilde{p}$ in period $t$. Furthermore, Seller $s^{\prime}$ and buyer $b$ ' have the same outside options as seller $s$ and buyer $b$ in all other periods as well.

${ }^{7}$ In the first session of each treatment we had two matching groups with 12 buyers and 12 sellers. In the second session we had only 22 subjects and implemented only one matching group. With 24 periods and matching groups of 6 buyers and 6 sellers some of the subjects interacted with the same opponent more than once. However, subjects did not know that they were divided in two matching groups, nor did they know whether and if so with whom they would interact more than once. Thus, repeated games effects are very unlikely.

${ }^{8}$ In each of these sessions we had 24 subjects and implemented two matching groups. 
Technical University of Munich. All experiments were computerized with the software z-Tree (Fischbacher 2007). Payoffs were measured in experimental points that were exchanged into EUR at the end of the experiment (100 points=EUR 1.50). On average, subjects earned about EUR 25 (US\$ 32 at the time of the experiments).

\section{Hypotheses}

We designed the experiment such that the strategic situation and the material payoffs of all players are exactly the same in the renegotiation game that is determined by the contracts in CT and the bargaining game that is set up exogenously in NCT. Thus, the traditional model of perfectly rational and selfish behavior (self-interest model) predicts the same outcome in both treatments. This is an immediate implication of the principle of subgame perfection.

Hypothesis 1 [Self-interest Model]: The renegotiation outcome in the Contract Treatment is the same as the bargaining outcome in the No Contract Treatment: The seller requests a markup of 49 or 50 , claiming (almost) the entire renegotiation surplus for himself, which is accepted by the buyer in equilibrium.

The literature on social preferences argues that many people are not purely self-interested but care also about the welfare of other people. Models of altruism (Andreoni and Miller, 2002), inequity aversion (Fehr and Schmidt, 1999) or minmax preferences (Charness and Rabin, 2002) maintain the assumption that players are perfectly rational but allow for more general utility functions. They assume that the utility function of a player depends not only on his own material payoff but also on the material payoffs of other players. Since the strategic situation and the material payoffs of all players are the same in both treatments, these models also predict that there is no difference in behavior across treatments. However, the hypothesized behavior is different from the prediction of the self-interest model.

Hypothesis 2 [Outcome-based Social Preferences]: The renegotiation outcome in the

Contract Treatment is the same as the bargaining outcome in the No Contract Treatment. However, a seller with outcome-based social preferences will leave up to 
50 percent of the overall surplus to the buyer. The lower the share offered to the buyer the higher is the probability of rejection.

Some more recent papers give up the assumption of perfectly rational behavior. In particular, Hart and Moore (2008) argue that contracts serve as reference points that may affect behavior. The Hart and Moore (2008) model is not directly applicable to our experiment. They consider atwill-contracts that cannot be renegotiated while we consider specific-performance contracts, which are frequently renegotiated. If we apply the spirit of the Hart-Moore approach to our setting, it predicts that each party feels entitled to get the entire surplus of renegotiation. The buyer feels entitled to have the good delivered at the right day. He is prepared to compensate the seller for higher costs, but not for paying anything in addition. In contrast the seller feels entitled to the entire social surplus of renegotiation, i.e. to a mark-up of 50. In our experiment, there is no possibility to shade, but the buyer can punish the seller by rejecting his renegotiation offer. Thus, with an initial contract in place the buyer is more likely to reject high markup offers than without an initial contract. Sellers anticipate this and will ask for lower markups in CT than in NCT.

Herweg and Schmidt (2012) offer a different theory of contracts as reference points that is more directly applicable to our setup. They consider a situation where a buyer and a seller write a specific performance contract that may turn out to be inefficient after the realization of the state of the world. Parties can renegotiate the initial contract, but they suffer from loss-aversion. Applied to our experiment the Herweg-Schmidt model predicts that if the degree of loss aversion is not too large parties will renegotiate to an efficient delivery date, but prices will be "sticky." Because the buyer feels a loss if the price is increased, he is more reluctant to accept a high markup. Sellers anticipate this behavior and ask for lower markups if there is an initial contract than if the same outside options have been assigned exogenously. Thus, both models generate the same hypothesis:

Hypothesis 3 [Contracts as Reference Points]: In the Contract Treatment, where the buyer and the seller agreed to an initial contract, the requested markup will be lower than in the No Contract Treatment, where no initial contract is in place.

Hart and Moore (2008) argue that the reference point effect is stronger if the initial contract has been agreed upon under competitive conditions. Competition provides an objective measure of 
what the buyer and the seller bring to the relationship. Thus if there is ex ante competition the initial contract has a stronger impact on expectations and entitlements than if there is no competition ex ante. This is stated in the next hypothesis.

Hypothesis 4 [Competition and Reference Points]:The effect of the initial contract is more pronounced if the contract was negotiated under competitive conditions than if the seller offers the initial contract as a monopolist.

\section{Negotiation vs. Renegotiation}

In this section we compare behavior in the renegotiation game starting at stage 2 of the Contract Treatment (CT) to bargaining behavior in the No Contract Treatment (NCT). Our experimental design ensures that the strategies available to both players and the material payoff functions are identical in both treatments. Recall that in CT, renegotiations take place if and only if (i) the seller's initial contract offer is accepted, (ii) the efficient day of delivery is not Wednesday, (iii) the buyer asks to change the day of delivery, and (iv) the seller does not insist to deliver on Wednesday. Thus, we first have to report what happened prior to entering possible renegotiations at stage 2 of CT.

\subsection{Initial Prices, Acceptance Decisions, and Entering Renegotiations}

In CT sellers offer a mean price of 64.3 at the initial contracting stage. Note that if Wednesday is the right day, a price offer of 60 shares the surplus equally between the buyer and the seller. In fact, as shown in Figure 1, 60 is the mode of the price distribution at stage 0. 88 percent (484 out of 552) of the initial contract offers are accepted. While initial price offers of less than 70 are almost always accepted (in 365 out of 370 cases), the rejection rate rises sharply for higher prices, and price offers above 75 are always rejected.

In 60 percent of all cases Wednesday is not the right day and an efficiency gain can be realized by changing the day of delivery. There are few cases in which the buyer did not ask for a change of the day of delivery or the seller insisted on trading on Wednesday so that the initial contract was executed. Altogether we consider 276 cases in which the parties entered the 
renegotiation game. ${ }^{9}$ In the following, we compare these 276 observations of renegotiation behavior in CT to the corresponding 276 cases of bargaining behavior in NCT.

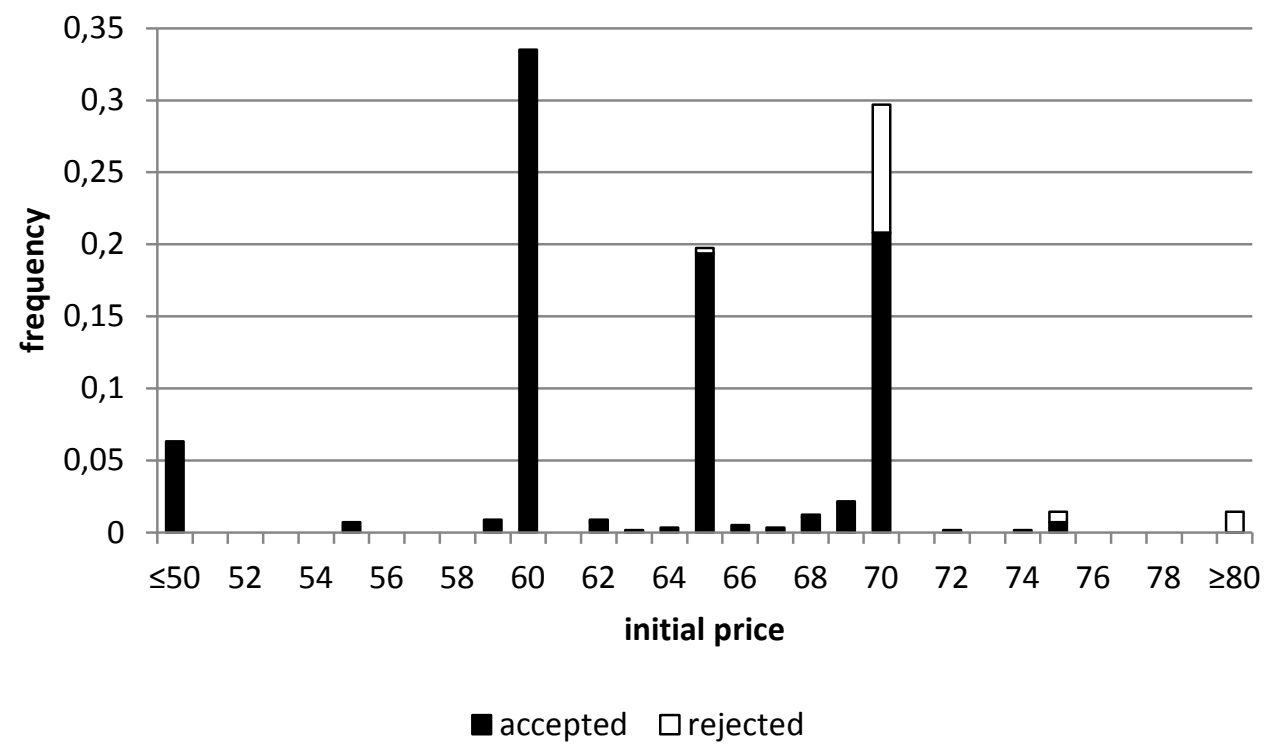

Figure 1: Distribution of initial price offers and acceptance decisions in CT.

\subsection{Markups with and without Ex-ante Contracts}

In the renegotiation game of $\mathrm{CT}$ and in the bargaining game of NCT the seller can either make a (re)negotiation offer,i.e., offer to deliver the good if the buyer agrees to a markup, or he can deliver the good without asking for a price change, in which case the markup is zero. Our main interest is whether sellers request different markups in CT than in NCT even though the strategies available to the players, the payoffs, and the threatpoint are exactly the same in both situations.

Result 1 (The Effect of Contracts on Markups): In the renegotiation game of the Contract Treatment sellers ask on average for a markup of 14.9, while the average markup in the negotiation game of the No-Contract Treatment is 27.0. Thus, the ex ante contract causes sellers to reduce their markups by highly significant 4.85 percent.In CT 20 percent of the sellers are willing to deliver at a markup of zero, more than twice as many as in NCT.

\footnotetext{
${ }^{9}$ There are also a few cases in which the seller did not want to trade in NCT. We disregard the corresponding cases in CT to ensure that we consider the same number of observations with exactly the same threatpoints in CT and NCT.
} 
Evidence for Result 1 is provided by Figure 2 that shows the full distribution of markups in both treatments. For non-negative markups the distribution of markups in NCT first-order stochastically dominates the distribution in $\mathrm{CT} .{ }^{10}$ A Kolmogorov-Smirnov test confirms that the distributions of the markups are not identical in CT and NCT $(\mathrm{p}<0.001)$.

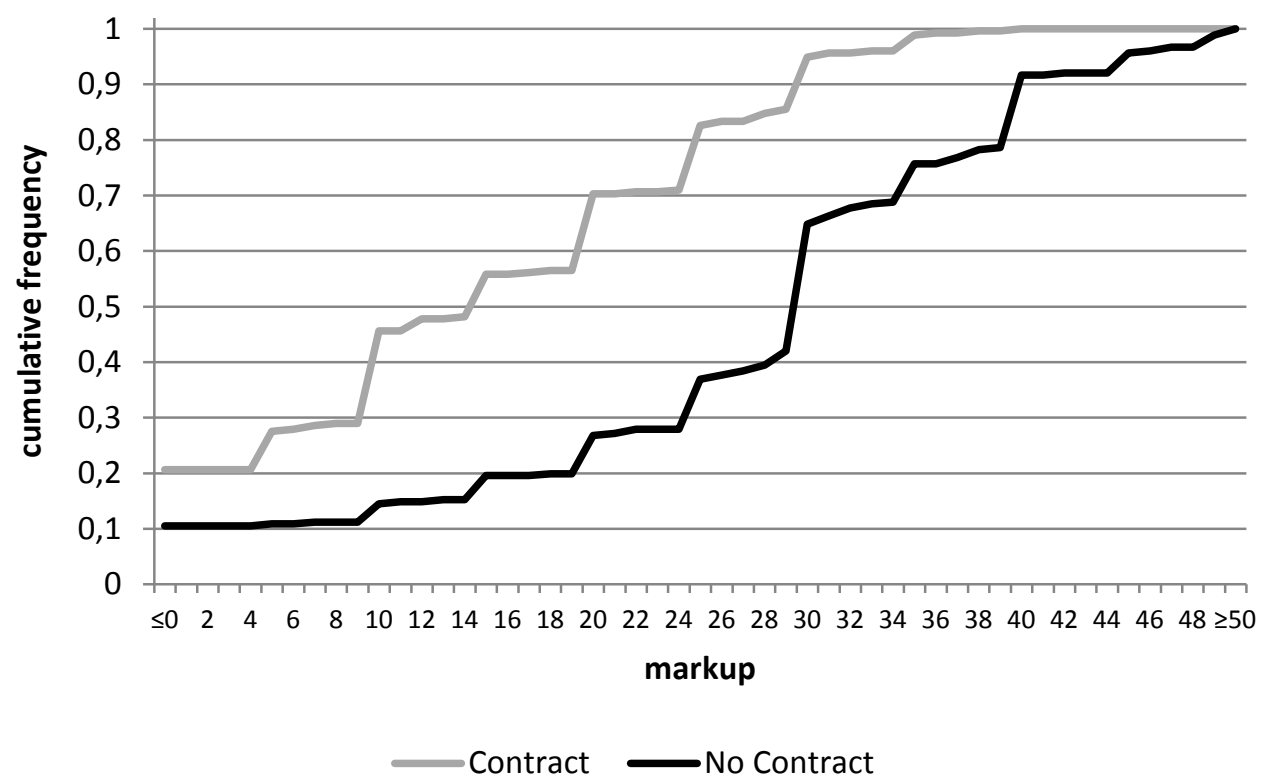

Figure 2: Cumulative frequency of markups in CT and NCT

Looking at individual seller averages (where we have 23 observations in each treatment) the difference between treatments is significant at the 1 percent level (rank sum test, $\mathrm{p}<0.001$ ). ${ }^{11}$ If we (conservatively) treat each matching group as an independent observation we still find that the difference in the means of the markup is significant at the 5 percent level (rank sum test, $\mathrm{p}=0.050$ ). Since we have three matching groups only, a higher level of significance cannot be obtained. ${ }^{12}$ The regression analysis reported in Table 1 that is discussed in detail in the next section also strongly confirms these differences. ${ }^{13}$

\footnotetext{
${ }^{10}$ In NCT we have four observations with a negative markup while the lowest markup is zero in CT. A negative markup arises in NCT if the seller asks for a price $\hat{p}$ that is smaller than the exogenously given price $p$. We suspect that subjects made a mistake here. Such a mistake is less salient in NCT than in CT where the subjects saw directly whether the markup was positive or negative.

${ }^{11}$ All tests reported in this paper are two-sided.

${ }^{12}$ All three matching group averages are lower in CT than in NCT.

${ }^{13}$ A possible confounding factor of our experimental design is that buyers self-select into the bargaining situation in CT because they have to make initial contract offers that are moderate enough to be accepted by the buyers. In the renegotiation game in CT we might thus have less "aggressive" buyers on average compared to the negotiation game in NCT where buyers are randomly allocated to the different bargaining situations. This possible sorting effect could explain the observed difference of the markups. However, even if we take measures to correct for the possible
} 
In CT the seller chooses to deliver the good on the right day without requesting any markup in 20.7 percent of all cases (57 out of 276). This happens predominantly (in 54 out of 57 cases) when the seller's costs to deliver on the right day are smaller or equal than 20 . This result suggests that at least some sellers feel obliged to deliver the good at the terms of the initial contract if they can do so at no additional cost. In contrast, in NCT the seller delivers at the exogenously given price in only 9.1 percent of the cases (25 out of 276). This difference is significant in a rank-sum test on matching group averages $\mathrm{p}<0.050) .{ }^{14}$

The bargaining situation in CT and NCT is akin to an ultimatum game where the seller offers a share of a given surplus to the buyer that the buyer can either accept or reject. The surplus to be divided is the increase of the buyer's valuation (50) minus the increase of the seller's cost (which may be negative). A closer look at the distribution of the share of the renegotiation surplus that the seller offers to the buyer shows that in CT the seller offers strictly more than 50 percent of the surplus to the buyer in 75 percent of all cases. In contrast, in a typical ultimatum game experiment it happens very rarely that the proposer offers more than 50 percent of the pie to the responder. In NCT this fraction goes down to 32 percent. $^{15}$

We now turn to the buyers' acceptance decision of the (non-zero) markup offers. We find that at the (re)negotiation stage 92.2 percent of all offers are accepted in CT and in 86.1 percent in NCT. A rank sum test on matching group averages shows that this difference is not significant $(p=0.127)$, which is confirmed by a rank sum test on individual buyer averages $(p=0.619)$. While there is no significant difference of rejection rates between the two treatments, there is a large and highly significant difference if we control for the size of the requested markup:

sorting effect, it cannot explain Result 1: In CT, about 12 percent of the initial contract offers are rejected, so that the 12 percent most "aggressive" sellers might not be present in the renegotiation game. Even if we disregard the 12 percent highest markups in NTC (coming from the most "aggressive" sellers), the average markup in the NCT amounts to 24.3, still an increase of 63.1 percent relative to CT. The rank sum test on the level of matching group averages remains significant at the 5 percent level and the Kolmogorov-Smirnov test remains significant at the 1 percent level. Similarly, if we disregard the 12 percent of the sellers with the highest average markups in NTC, the rank sum test at the level of individual sellers remains significant that the 1 percent level. Finally, in Section 5 below we consider treatments with competition between buyers at the initial offer stage. In these treatments we observe no rejections of initial contract offers, i.e. no sorting, but replicate the effect of contracts on markups.

${ }^{14}$ All three matching group averages are higher in CT than in NCT. However, a rank-sum test on individual seller averages shows no significant difference $(\mathrm{p}=0175)$.

${ }^{15}$ For an overview of behavior in ultimatum games see, e.g., Camerer 2003, Ch. 2. In our bargaining game the buyer and the seller have asymmetric outside options. In most cases, the seller's outside option payoff is higher than the buyer's outside option. This might explain why even in NCT many sellers offer more than 50 percent of the surplus to the buyer. 
Result 2 (The Effect of Contracts on Rejection Behavior): For given requested markups buyers are significantly more likely to reject the offer in the Contract Treatment than in the No Contract Treatment. However, because sellers ask for much lower markups in CT the overall rejection rate is not significantly different in CT than in NCT.

The first part of Result 2 is illustrated by Figure 3. In NCT, there are virtually no rejections of markups of 25 or less ( 1 out of 77 observations), while the average rejection rate for these markups is about 6 percent in CT (10 out of 171 observations). Also for higher markups, in the markup bins shown in the figure, the rejection rate is about the same or higher in CT than in NCT (note that there are no observations of markups larger than 40 in CT).

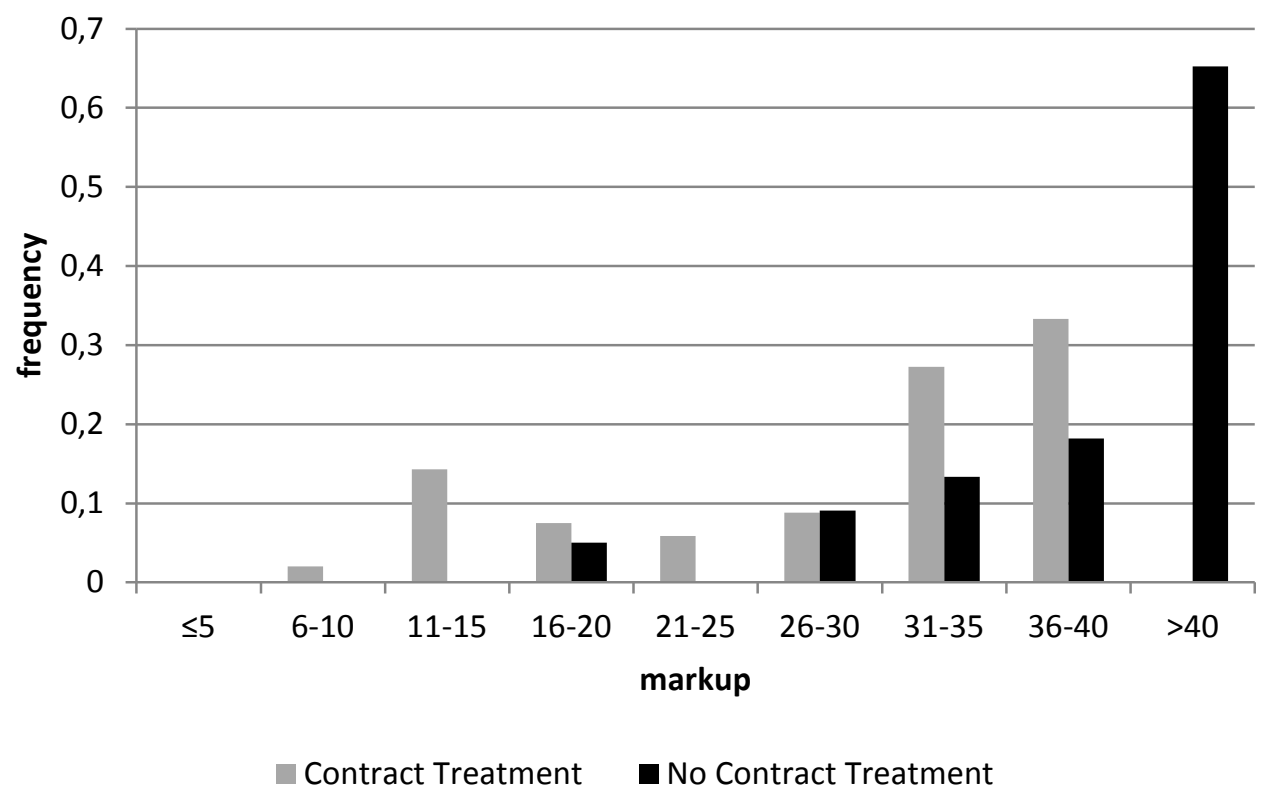

Figure 3: Rejection rates in CT and NCT for given markups.

The regression analysis in Table 2, reported in detail in Section 5 below, confirms this observation. These regressions show that for given markups an initial contract has a highly significant negative effect on the probability of acceptance. The size of the markup also has a highly significant negative effect. However, buyers are more willing to accept a higher markup if the initial contract is very "unfair" in the sense that a higher markup is required to equalize final payoffs. The analysis of the buyers' acceptance behavior shows that buyers are much more reluctant to accept high markups in CT than to accept the same markups in NCT, even though final payoffs and the threatpoints in case of bargaining breakdown are the same. 
To summarize, we find very large and highly significant treatment effects. Because the strategies available to both players and the monetary payoffs are identical in CT and NCT these treatment effects cannot be due to the impact of the initial contract on the threatpoint. Instead, Result 1 shows that the mere fact that the parties had written an initial contract is causal for the much smaller increase in prices in the renegotiations. The initial contract makes prices sticky. This rejects Hypotheses 1 and 2 but is consistent with Hypothesis 3. Moreover, we find that the presence of initial contracts causally affects the buyers' acceptance behavior. Result 2 shows that buyers are less willing to accept price increases on top on an initial contract than equally sized prices in the treatment without an initial contract, which is again consistent with Hypothesis 3 but not with Hypotheses 1 and 2.

\section{The Effect of Competition}

In this section we address the claim of Hart and Moore (2008) that a contract that was written under competitive conditions provides a stronger reference point because it is a more objective measure of what a buyer and a seller brings to a trading relationship. If there is competition at the initial contracting stage, the initial contract therefore has a stronger impact on expectations and entitlements than if there is no competition. We test this hypothesis by conducting treatments with competition among sellers at the initial contracting stage.

The treatments with competition are identical to the treatments without competition except for the fact that at the initial contracting stage two sellers compete for the right to be able to make a contract offer to the buyer. The price is determined by an ascending clock auction. The starting price of the auction is zero. The price increases by one unit every second. The first seller to stop the clock wins the auction and makes a trade offer at the auction price to the buyer which the buyer can either accept or reject. The other seller gets a payoff of 0 . Recall that in CT, a monopolistic seller can choose the price freely and make a take-it-or-leave-it offer to the buyer. In contrast, in the Contract\&Competition Treatment (CT\&COMP), only the seller who wins the auction makes an offer and this offer is determined by the auction. In all other respects, CT and CT\&COMP are identical.

We find that the mean initial price is 24.8 in CT\&COMP, compared to 64.3 in CT. The much lower initial price reflects the strong competition between sellers at the initial stage. In 
CT\&COMP all initial contract offers are accepted. If Wednesday is not the right day there are again a few cases in which the buyer did not ask for a change of the day of delivery or in which the seller insisted on trading on Wednesday so that the initial contract was executed. Altogether we consider 222 cases in which the parties entered the renegotiation game. ${ }^{16}$

Our main interest is on the markups that are charged on top of the initial price offer. Note that in both treatments, CT and CT\&COMP, the seller can make a take-it-or-leave-it renegotiation offer to the buyer, and that the buyer's surplus that is up for grasp is 50 in both cases. Nevertheless, the behavior of the sellers is very different in the two treatments.

\section{Result 3 (The Effect of Ex ante Competition on Markups): Initial prices are} much lower in in the Contract\&Competition Treatment (24.8) than in the Contract Treatment with a monopolistic seller (64.3). However, sellers try to compensate for the lower initial prices by charging much higher markups. The average markup in CT\&COMP is 35.6, more than twice as high as the average markup of 14.9 in CT. Furthermore, in CT\&COMP sellers deliver on the right day without charging a markup much less often than in CT.

The difference in markups is highly significant ${ }^{17}$ and economically important. The result shows that there is a cost to the buyer to having strong competition at the contracting stage and to leaving little of the surplus to the seller in the initial contract. The cost is that after the buyer is locked in with the seller (i.e. after Williamson's "fundamental transformation") the seller will behave much more aggressively at the renegotiation stage if he was squeezed at the initial stage. Furthermore, in CT\&COMP sellers deliver on the right day without charging a markup in only 4.2 percent of all cases. A rank-sum test on matching group averages shows that the difference is significant $(\mathrm{p}=0.034){ }^{18}$

To be sure, a monopolistic seller who got a large share of the surplus at the initial stage may also request a high markup in the renegotiation game. However, in our experiment sellers

\footnotetext{
${ }^{16}$ Even though we have the same number of sessions for the treatments with competition than without competition, we have fewer observations with competition because always two sellers are paired with one buyer. Moreover, as in NCT, in NCT\&COMP a few sellers decided not to trade. We again disregard the corresponding cases in CT\&COMP to ensure the same number of observations with exactly the same threatpoints in CT\&COMP and NCT\&COMP.

${ }^{17}$ Rank sum test on matching group averages, $\mathrm{p}=0.034$ (all four matching group averages in NCT are higher than the three matching group averages in CT); rank sum test on individual seller averages, $p \leq 0.001$.

${ }^{18}$ All three matching group averages in CT are higher than the four matching group averages in CT\&COMP. A ranksum test on individual seller averages confirms this finding $(\mathrm{p}=0.005)$.
} 
don't do this. If they got a good deal initially they charge modest mark-ups. They go for very high markups only if they got a bad deal in the initial contract. Thus, a large fraction of the financial gain that buyers achieved by ex ante competition is lost again in the renegotiation game if Wednesday is not the right day.

Even though sellers behave more aggressively in CT\&COMP than in CT, it cannot be concluded that the initial contract has less of an effect on the renegotiation outcome in CT\&COMP than in CT. A clean test of the effect of the initial contract requires a new treatment that is identical to CT\&COMP except for the fact that there is no initial contract that determines the threatpoint of the bargaining game but that the threatpoint is imposed exogenously. This new treatment is called the No Contract\&Competition Treatment (NCT\&COMP). It is derived from CT\&COMP in the same way as NCT is derived from CT. ${ }^{19}$ Thus, the experimental design makes sure that the strategies available to all players, the monetary payoffs and the threatpoints are identical in CT\&COMP and in NCT\&COMP in every period and for every group of two sellers and one buyer. Nevertheless, the next result shows that there is a large difference in behavior.

\section{Result 4 (The Effect of Contracts under Competition): In the No Contract\&Competition Treatment the average markup is 40.0, while it is only 35.3 in the Contract\&Competition Treatment. This difference is highly significant. Thus, the initial contract that was formed under competitive conditions causes sellers to offer markups that are 11.75 percent lower than the markups offered if there is no initial contract.}

We again find the same qualitative difference between the treatment with and the treatment without an initial contract. Looking at individual seller averages this difference is highly significant at the 1 percent level (rank sum test, $p=0.002$ ). This is confirmed if we look at matching group averages. Here the difference is significant at the 10 percent level (rank sum test, $\mathrm{p}=0.083$ ).

\footnotetext{
${ }^{19}$ For each group of two sellers and one buyer in CT\&COMP the outcome of the auction and the price signed in the contract gives rise to a vector of outside options $\left(\underline{M}^{B}=50-p, \underline{M}_{1}^{S}=p-20, \underline{M}_{2}^{S}=0\right)$, where seller 1 denotes the seller who was successful in the auction. In the corresponding group of two sellers and one buyer in NCT\&COMP these outside options are assigned exogenously to the buyer and to seller 1, while seller 2 is informed that he cannot trade in this period and gets a payoff of zero.
} 
Figure 4, the equivalent to Figure 2 in Section 4, shows the cumulative distribution of all markups in CT\&COMP and NCT\&COMP. It is evident that there is again a clear shift in the distribution and that the non-negative markups in NCT\&COMP (almost) first order stochastically dominate markups in CT\&COMP. ${ }^{20}$ A Kolmogorov-Smirnov test confirms that the distributions of the markups are not identical in CT\&COPM and NCT\&COMP $(\mathrm{p}<0.001)$.

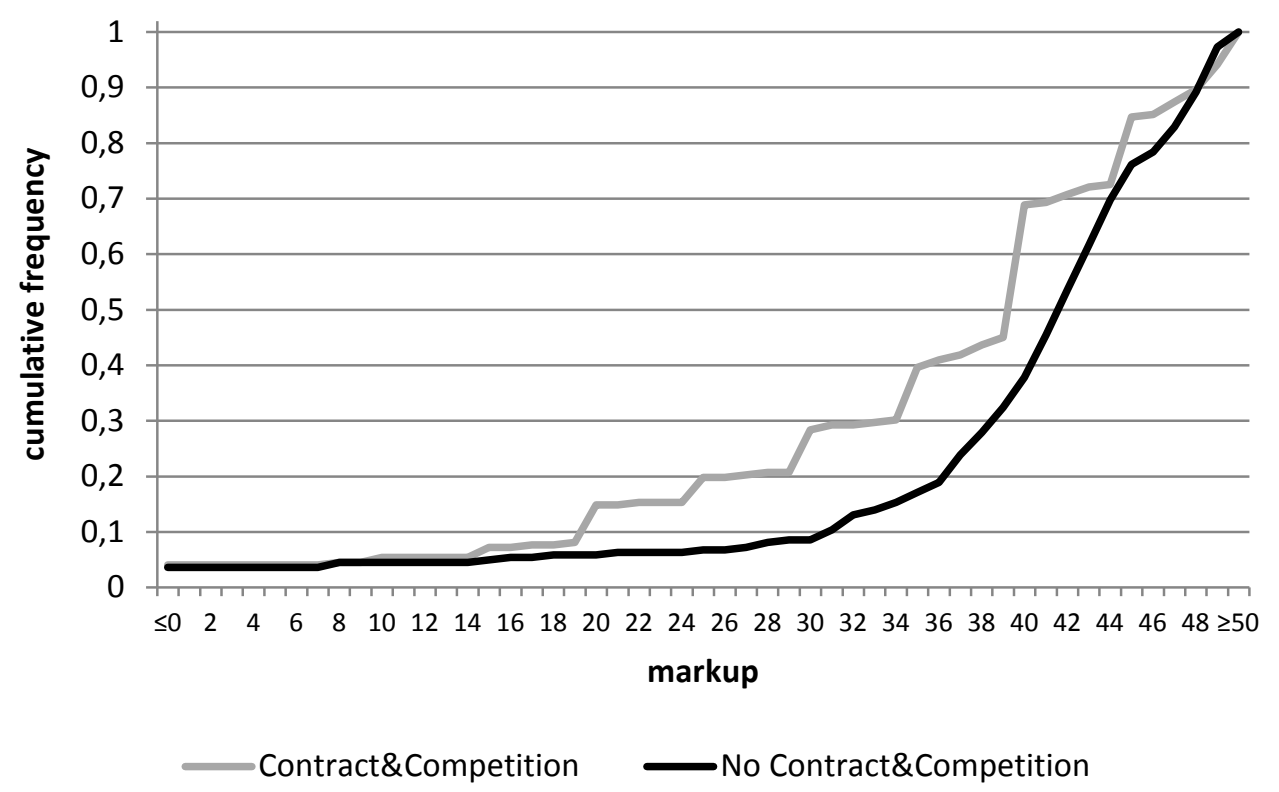

Figure 4: Cumulative frequency of markups in treatments CT\&COMP and NCT\&COMP.

The regression analysis in Table 1 confirms these observations. The dependent variable in all regressions is the absolute size of the markup in our four treatments. The No Contract Treatment serves as the baseline condition. CONTRACT is a dummy variable taking on value 1 if an observation comes from one of the two treatments with an ex-ante contract (CT and CT\&COMP). COMP is a dummy variable taking on value 1 if the observation comes from one of the two treatments with competition (CT\&COMP and NCT\&COMP). The interaction of these two dummy variables, CONTRACT $\times$ COMP, thus takes on value 1 if an observation comes from CT\&COMP. The variable FairMarkup denotes the size of the markup that would equalize final payoffs between the buyer and the seller when the good is delivered on the right day, given the initial price and the cost realization on the right day of delivery.

\footnotetext{
${ }^{20}$ We have a single observation of a negative markup in NCT\&COMP while all markups in CT\&COMP are weakly positive. The cumulative frequency of the non-negative markups in NCT\&COMP lies below the one in CT\&COMP except for the frequency at a markup of 49.
} 
Table 1: Regression Analysis of Markups

\begin{tabular}{|c|c|c|c|c|c|}
\hline VARIABLES & $\begin{array}{c}\text { (1) } \\
\text { markup }\end{array}$ & $\begin{array}{c}(2) \\
\text { markup }\end{array}$ & $\begin{array}{c}\text { (3) } \\
\text { markup }\end{array}$ & $\begin{array}{c}(4) \\
\text { markup }\end{array}$ & $\begin{array}{c}(5) \\
\text { markup }\end{array}$ \\
\hline CONTRACT & $\begin{array}{l}-8.639 * * * \\
(2.397)\end{array}$ & $\begin{array}{c}-8.643 * * * \\
(1.575)\end{array}$ & & & $\begin{array}{c}-11.13 * * * \\
(2.279)\end{array}$ \\
\hline COMP & & & $\begin{array}{c}16.84 * * * \\
(1.781)\end{array}$ & $\begin{array}{c}-0.783 \\
(3.577)\end{array}$ & $\begin{array}{l}-0.067 \\
(4.555)\end{array}$ \\
\hline CONTRACT $\times$ COMP & & & & & $\begin{array}{c}2.721 \\
(6.800)\end{array}$ \\
\hline FairMarkup & & $\begin{array}{c}0.424 * * * \\
(0.0346)\end{array}$ & & $\begin{array}{c}0.440 * * * \\
(0.0815)\end{array}$ & $\begin{array}{l}0.387 * \\
(0.204)\end{array}$ \\
\hline FairMarkup $\times$ COMP & & & & & $\begin{array}{l}-0.073 \\
(0.230)\end{array}$ \\
\hline FairMarkup $\times$ CONTRACT & & & & & $\begin{array}{c}0.239 \\
(0.222)\end{array}$ \\
\hline $\begin{array}{l}\text { FairMarkup } \times \text { CONTRACT } \times \\
\text { COMP }\end{array}$ & & & & & $\begin{array}{l}-0.126 \\
(0.267)\end{array}$ \\
\hline Constant & $\begin{array}{l}32.79 * * * \\
(1.406)\end{array}$ & $\begin{array}{c}26.97 * * * \\
(1.362)\end{array}$ & $\begin{array}{c}20.97 * * * \\
(1.581)\end{array}$ & $\begin{array}{c}22.77 * * * \\
(1.487)\end{array}$ & $\begin{array}{l}28.61 * * * \\
(1.533)\end{array}$ \\
\hline Observations & 996 & 996 & 996 & 996 & 996 \\
\hline R-squared & 0.076 & 0.414 & 0.286 & 0.338 & 0.433 \\
\hline
\end{tabular}

Notes: The table shows OLS regressions that cluster on individual sellers. Robust standard errors are shown in parentheses. F-tests show that FairMarkup and the interactions with FairMarkup are jointly highly significant in regressions (5) and (6); *** $\mathrm{p}<0.01, * * \mathrm{p}<0.05, * \mathrm{p}<0.1$

Regression 1 shows that the size of the markup is substantially and highly significantly lower in treatments with ex-ante contracts than in treatments without ex-ante contracts. The regression constant shows that the size of the markup is about 32.8 in the treatments without contracts. Hence the coefficient of -8.6 of the CONTRACT dummy indicates a reduction in the size of the markup of more than 25 percent. Regression 2 shows that FairMarkup has significant explanatory power. If FairMarkup increases by 1 point, the actual markup increases 0.42 points, i.e. fairness motives explain more than 40 percent of the size of the markup. Importantly, the size and significance of the effect of CONTRACT on markups remains unchanged if we control for FairMarkup. This is to be expected because the distribution of FairMarkup is by design identical in the treatments with and without initial contracts.

Regression 3 shows that the size of the markup is substantially and highly significantly higher in treatments with competition than in treatments without competition. However, if we 
control for FairMarkup we find in Regression 4 that the effect of competition is fully explained by the lower initial prices that result from competition at the initial stage. That is, competition as such does not affect the size of the markups.

These basic findings are confirmed by Regression 5 that shows the fully interacted model. It can be seen that the effect of CONTRACT remains highly significant and even increases in size. The effect of competition as such remains small and insignificant. The interaction of the competition dummy with the contract dummy, CONTACT $\times$ COMP, measures whether the effect of contracts on the size of the markup is different in the treatment with competition compared to the treatment without competition. We cannot confirm Hypothesis 4 stating that the reference point effect of contracts is more pronounced if the contract was initially concluded under competitive conditions. If anything, we find that the effect of contracts on markups is somewhat smaller under competition, indicated by the positive coefficient of CONTRACT $\times$ COMP, but this difference is not significant. ${ }^{21}$

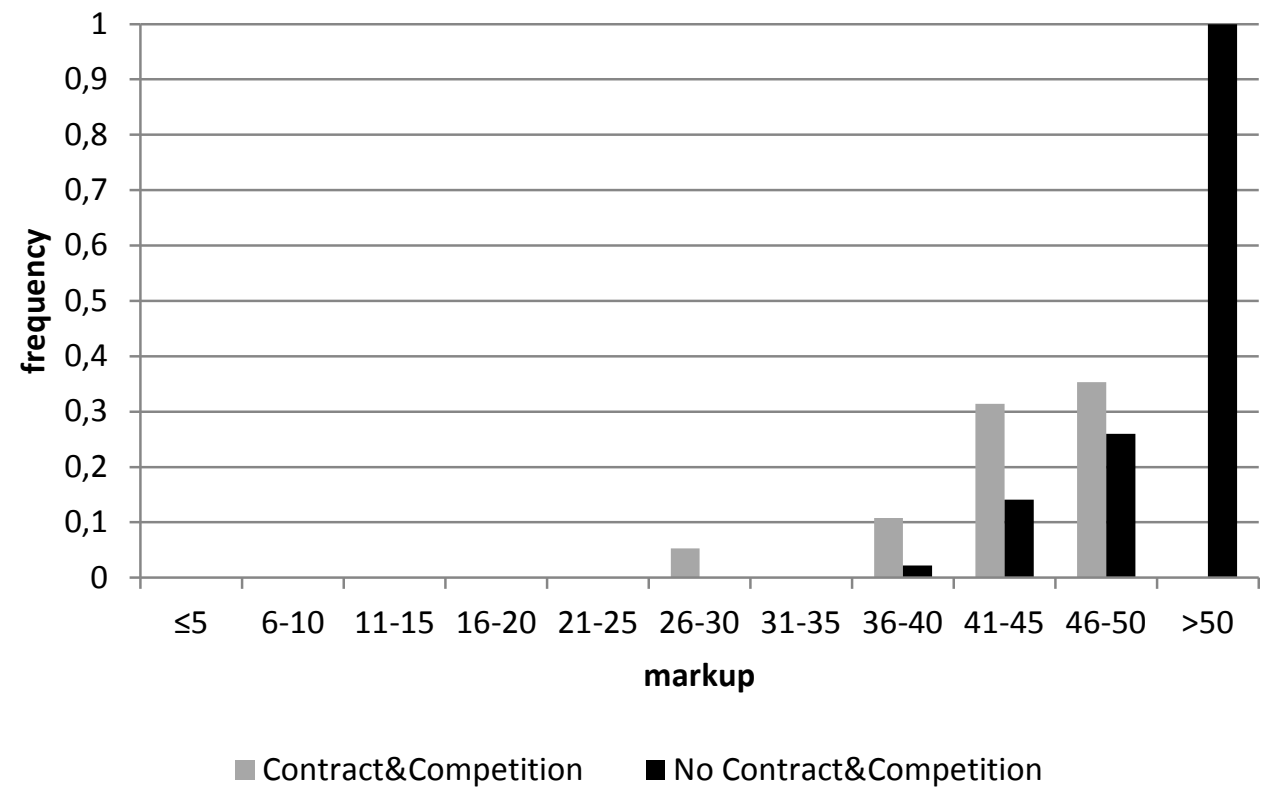

Figure 5: Rejection rates in CT\&C and NCT\&C for given markups.

\footnotetext{
${ }^{21}$ An F-test shows that FairMarkup and the interactions of FairMarkup with CONTRACT, with COMP, and with CONTRACT $\times$ COMP are jointly highly significant $(\mathrm{p}<0.001)$, while the single interactions do not show a significantly differential effect of FairMarkup on markup in the treatments relative to the baseline NCT (also the interactions of FairMarkup with CONTRACT and CONTRACT $\times$ COMP are jointly insignificant ( $\mathrm{p}=0.329$ ). Furthermore, there are no time effects. Including period dummies in Regression (5) does not affect the results. Note finally that the smaller difference in markups (or our failure not to find a larger difference) in the treatments with competition is not due to a ceiling effect. Relative to NCT\&COMP, there is ample "space" for markups in CT\&COMP to be lower; even more than in CT relative to NCT.
} 
Let us now turn to the buyers' acceptance decisions. We find that in the bargaining game 85.4 percent of all offers are accepted in CT\&COMP and in 86.4 percent in NCT\&COMP. A rank sum test on matching group averages shows that this difference is not significant $(\mathrm{p}=0.773)$, which is confirmed by a rank sum test on individual buyer averages $(p=0.530)$. However, Figure 6 illustrates that for given markups the rejection rates are higher in CT\&COMP than in NCT\&COMP. Thus, buyers are more reluctant to accept a given markup if there was an ex ante contract.This is confirmed by the probit and logit regressions on the buyers' acceptance decisions reported in Table 2. They show that the coefficient of CONTRACT is negative and highly significant with a marginal effect of about 10 percent. Not surprisingly the effect of Markup is also negative and highly significant. FairMarkup has a positive effect. Thus, a higher markup reduces the probability of acceptance, but buyers are more likely to accept a high markup if the threatpoint payoffs are very unequal, i.e. if a high markup is required to achieve equality. Most importantly, however, COMP and CONTRACT $\times$ COMP are not significant in any of our regressions. Thus, competition on its own or in conjunction with an initial contract does not affect the buyer's acceptance decision. Again, this finding is consistent with Hypothesis 3, but it does not confirm Hypothesis 4.

Table 2: Regression Analysis of Buyers' Acceptance Decisions

\begin{tabular}{lcccc}
\hline & $\begin{array}{c}(1) \\
\text { probit }\end{array}$ & $\begin{array}{c}(2) \\
\text { probit } \\
\text { marginal effects }\end{array}$ & $\begin{array}{c}(3) \\
\text { logit }\end{array}$ & $\begin{array}{c}\text { logit } \\
\text { marginal effects }\end{array}$ \\
VARIABLES & accept & accept & accept & accept \\
\hline CONTRACT & $-0.721^{* * *}$ & $-0.104 * * *$ & $-1.255^{* * *}$ & $-0.0846^{* *}$ \\
COMP & $(0.228)$ & $(0.038)$ & $(0.428)$ & $(0.034)$ \\
& -0.489 & -0.069 & -0.727 & -0.048 \\
CONTRACT×COMP & $(0.385)$ & $(0.060)$ & $(0.717)$ & $(0.053)$ \\
& 0.421 & 0.050 & 0.726 & 0.040 \\
Markup & $(0.329)$ & $(0.035)$ & $(0.613)$ & $(0.031)$ \\
FairMarkup & $-0.086^{* * *}$ & $-0.012^{* * *}$ & $-0.161 * * *$ & $-0.010^{* * *}$ \\
Constant & $(0.012)$ & $(0.002)$ & $(0.023)$ & $(0.002)$ \\
& $0.033^{* * *}$ & $0.005 * * *$ & $0.055^{* * *}$ & $0.004 * * *$ \\
& $(0.007)$ & $(0.001)$ & $(0.013)$ & $(0.001)$ \\
Observations & $4.137 * * *$ & & $7.606 * * *$ & \\
\hline
\end{tabular}

Notes: The table shows regressions on the buyers' acceptance decisions. Robust standard errors clustering on individual buyers are shown in parentheses. $* * * \mathrm{p}<0.01$, ** $\mathrm{p}<0.05, * \mathrm{p}<0.1$ 


\section{Conclusions}

Our experimental results provide causal evidence on two effects of contracts on renegotiation behavior. First, a contract has a causal effect on economic behavior that goes beyond its impact on the threatpoint of renegotiation. We find that sellers charge significantly lower markups in the renegotiation of an initial contract than in an otherwise identical bargaining situation in which no initial contract exists. Furthermore, buyers are more likely to reject given markups if there is an initial contract. This is consistent with the hypothesis that contracts provide reference points that shape expectations and entitlements. Second, the degree of competition at the initial contracting stage affects how the surplus of renegotiation is split, but it does not affect the power of the contract as a reference point. If sellers face more competition ex ante they try to compensate for the lower initial price by making more aggressive offers in the renegotiation game. But comparing behavior in the renegotiation game if a contract has been written under competitive conditions to behavior in an otherwise identical bargaining game without a prior contract shows that the effect of the initial contract is not significantly different with competition than without competition.

These results are potentially of great importance for the optimal design of contracts, organizations, and other governance structures. For example, if contracts make prices "sticky" then the hold-up problem is less severe than predicted by the standard self-interest model. Furthermore, if ex ante competition does not strengthen the power of the contract but rather induces sellers to behave more aggressively in the renegotiation game, then it is less valuable for buyers to induce ex ante competition. Our results open up the door for many other important questions. Given that our paper established that contracts have a causal effect on renegotiation behavior that goes beyond the threatpoint effect, we would like to better understand whether different contracts have different effects. Are formal contracts more powerful than informal agreements? Do contracts on trade have a different effect than contracts on the allocation of ownership rights or the assignment of decision rights? Most importantly, what are the costs of writing an initial contract? Under what circumstances do initial contracts cause renegotiation to be more or less efficient? Answering these exciting questions is left to future research. 


\section{References}

Andreoni, James and John H. Miller. 2002. "Giving According to GARP: An Experimental Test of the Consistency of Preferences for Altruism." Econometrica, 70(2): 737-53.

Brandts, Jordi, Gary Charness, and Matthew Ellman. 2012. "Let's Talk: How Communication affects Contract Design." mimeo.

Camerer, Colin. 2003. Behavioral Game Theory, Princeton: Princeton University Press.

Charness, Gary and Matthew Rabin. 2002. "Understanding Social Preferences with Simple Tests." The Quarterly Journal of Economics, 117(3): 817-69.

Erlei, Mathias and Christian Reinhold. 2011. "To Choose or Not to Choose: Contracts, Reference Points, Reciprocity, and Signaling." mimeo.

Fehr, Ernst, Oliver Hart, and Christian Zehnder. 2009. "Contracts, Reference Points, and Competition-Behavioral Effects of The Fundamental Transformation." Journal of the European Economic Association, 7(2-3): 561-72.

Fehr, Ernst, Oliver Hart, and Christian Zehnder. 2011. "Contracts as Reference Points Experimental Evidence." American Economic Review, 101(2), 493-525.

Fehr, Ernst, Oliver Hart, and Christian Zehnder. 2012. "How Do Informal Agreements and Renegotiation Shape Contractual Reference Points?” mimeo.

Fehr, Ernst and Klaus M. Schmidt. 1999. "A Theory of Fairness, Competition, and Cooperation." The Quarterly Journal of Economics, 114(3): 817-68.

Fischbacher, Urs. 2007. "z-Tree: Zurich Toolbox for Ready-made Economic Experiments." Experimental Economics, 10(2): 171-78.

Grossman, Sanford J. and Oliver D. Hart. 1986. "The Costs and Benefits of Ownership: A Theory of Vertical and Lateral Integration." Journal of Political Economy, 94(4): 691-719. Hart, Oliver. 2009. "Hold-Up, Asset Ownership, and Reference Points." Quarterly Journal of Economics, 124(1): 267-300.

Hart, Oliver and Bengt Holmström. 2010. "A Theory of Firm Scope.” Quarterly Journal of Economics, 125(2): 483-513.

Hart, Oliver and John Moore. 1988. "Incomplete Contracts and Renegotiation." Econometrica, 56(4): 755-85.

Hart, Oliver and John Moore. 1990. "Property Rights and the Nature of the Firm." The Journal of Political Economy, 98(6): 1119-58. 
Hart, Oliver and John Moore. 2008. “Contracts as Reference Points.” Quarterly Journal of Economics, 123(1-48).

Herweg, Fabian and Klaus M. Schmidt. 2012. "A Theory of Inefficient Ex-post Renegotiation.” mimeo.

Hoppe, Eva I. and Patrick W. Schmitz. 2011. "Can Contracts Solve the Hold-up Problem? Experimental Evidence.” Games and Economic Behavior, 73: 186-99.

Iyer, Rajkamal and Antoinette Schoar. 2010. "Incomplete Contracts and Renegotiation: Evidence from a Field Audit." MIT LFE Working Paper LFE-0713-10. 